Research

\title{
Combining partial liver resection and local ablation of liver tumours: a preliminary Dutch experience Bram Fioole ${ }^{1}$, Maarten C Jansen ${ }^{2}$, Frederieke H van Duijnhoven ${ }^{3}$, Richard van Hillegersberg ${ }^{1}$, Thomas $M$ van Gulik² and Inne HM Borel Rinkes*1
}

Address: ${ }^{1}$ Department of Surgery, University Medical Centre Utrecht, Utrecht, The Netherlands, ${ }^{2}$ Department of Surgery, Academic Medical Centre, Amsterdam, The Netherlands and ${ }^{3}$ Department of Surgery, Leiden University Medical Centre, Leiden, The Netherlands

Email: Bram Fioole - bfioole@planet.nl; Maarten C Jansen - m.c.jansen@amc.uva.nl; Frederieke H van Duijnhoven - f.h.van_duijnhoven@lumc.nl; Richard van Hillegersberg - r.vanhillegersberg@umcutrecht.nl; Thomas M van Gulik - t.m.vangulik@amc.uva.nl; Inne HM Borel Rinkes* - i.h.m.borelrinkes@umcutrecht.nl

* Corresponding author

Published: 17 July 2006

World Journal of Surgical Oncology 2006, 4:46 doi:10.1186/1477-7819-4-46

This article is available from: http://www.wjso.com/content/4///46

(C) 2006 Fioole et al; licensee BioMed Central Ltd.

This is an Open Access article distributed under the terms of the Creative Commons Attribution License (http://creativecommons.org/licenses/by/2.0), which permits unrestricted use, distribution, and reproduction in any medium, provided the original work is properly cited.

\begin{abstract}
Background: The combination of partial liver resection and radiofrequency ablation (RFA) is a novel concept in the treatment of unresectable liver malignancies. The aim of this study is to evaluate the results of this combined strategy in the Netherlands.

Methods: Thirty-five patients treated with a combination of partial liver resection and RFA were identified from a prospectively registered pooled multicentre database. All patients were operated between June 1999 and November 2003 in 8 medical centres in the Netherlands. Main outcome parameters were morbidity, mortality, local success rate, and survival.

Results: Thirty-seven operations were performed in 35 patients. The group consisted of 20 male and 15 female patients with a median age of 59 years (range 4I-76). Seventy-six lesions were resected and RFA was performed to ablate 82 unresectable liver tumours. Twelve patients developed a total of 24 complications, resulting in an overall perioperative morbidity rate of $32 \%$. In two patients major complications resulted in postoperative death (postoperative mortality rate $5.4 \%$ ). Local success rate after RFA was $88 \%$ and the estimated I-, 2- and 3-year overall survival rates were $84 \%, 70 \%$ and $43 \%$, respectively.
\end{abstract}

Conclusion: This strategy should only be performed following strict patient selection and within the context of prospective clinical trials.

\section{Background}

Partial liver resection is a well established treatment for primary and secondary malignancies of the liver $[1,2]$. In a selected population this is the sole potentially curative treatment and is associated with reported 5-year survival rates between 18 and 38\% [3-5]. However, the great majority of patients are not amenable to partial liver resection. Reasons to exclude patients for resection are extrahepatic disease, tumour location, inadequate functional hepatic reserve or proximity to major vascular structures. 
In recent years, locally ablative therapies have been used as an alternative treatment for unresectable liver tumours. The most widely used technique is radiofrequency ablation (RFA). With this method a radiofrequent current is applied through a needle electrode inserted directly into the tumour, with the aim of destroying all malignant cells. This technique is considered safe and efficient [6,7]. RFA is a low risk procedure, with mortality rates of about 0.5 $\%$ and complication rates between 6.9 and $9.8 \%$ [8-11]. However, especially following percutaneous RFA, local recurrence rates up to $40 \%$ are reported in large series [12$14]$. Tumour recurrences at other sites are common (28$70 \%$ ), probably caused by negative patient selection $[12,13,15]$. The overall outcome after RFA is difficult to interpret, since results vary widely and follow up data are immature.

Partial liver resection combined with RFA is a novel approach used in patients with otherwise unresectable lesions. Following resection, the remaining unresectable liver tumours can be ablated, while preserving adequate hepatic reserve. Although RFA has not yet proven to be potentially curative, more patients become candidates for surgical treatment by combining techniques with the purpose of complete clearance of intrahepatic tumour.

The objective of this study was to determine the results of hepatic resection combined with RFA in the Netherlands with emphasis on perioperative morbidity and mortality, recurrence rates and survival. The results were compared with those reported in the literature.

\section{Methods}

Patients were selected from our prospectively recorded multicentre database. Thirty-five patients were identified who had been treated with a combination of partial liver resection and RFA. All patients were operated between June 1999 and November 2003 in 8 medical centres in the Netherlands.

Preoperative work up consisted of a baseline history and physical examination, serum laboratory tests, chest radiograph or chest computed tomography (CT) when indicated, liver ultrasonography (US) or abdominopelvic imaging with $\mathrm{CT}$, magnetic resonance imaging (MRI) or positron emission tomography (PET). The volume of the remnant liver was assessed preoperatively. At least 30$35 \%$ of functional liver parenchyma should be preserved. Patients were considered unresectable based on advanced bilobar tumour distribution, inadequate functional hepatic reserve or proximity to major vascular structures. In all patients complete tumour clearance was not possible without the addition of RFA.
All patients underwent partial liver resection and RFA during laparotomy by an experienced liver surgeon. Intraoperative US was performed prior to the resection and RFA to document and target the lesions. During RFA, US was used to guide placement of the RF needle into the lesion and to monitor the effect of the treatment. Routinely, ultrasonic dissection technique was used to perform partial liver resection. Three different RF systems were used in the 8 medical centres (Radionics, Radiotherapeutics and RITA Medical Systems, respectively). Specific RFA protocols, designed by each of the three manufacturers, were used for each system according to manufacturer recommendations. A safety margin of $0.5-1.0 \mathrm{~cm}$ was aimed for in surgery as well as in RFA.

Medical records were reviewed for demographics, prior treatment, co-morbidity, tumour histology, number, size and distribution of tumours, type and extent of resection, application of Pringle manoeuvre, operative blood loss and length of hospital stay. Co-morbidity was defined as disease associated with an increased risk for operative complications.

Main outcome parameters were morbidity, mortality, recurrence and survival. Complications were considered major, when 1) life threatening if left untreated, 2) leading to substantial disability, or 3) resulting in hospital readmission or substantially lengthened hospital stay [16]. All other complications were considered minor. All complications following a procedure were registered. When complications were clearly caused exclusively by the ablation procedure they were considered RFA-related. Liver failure was defined as a progressive increase of serum bilirubin and the prothrombin time [17]. Postoperative mortality was defined as in-hospital mortality. Follow up was obtained by multiphasic CT or MRI at 3-4 month intervals following therapy. Recurrence was defined as newly developed tumours in untreated liver segments. Local tumour progression was defined as progression of residual unablated tumour or recurrence of tumour in the RFA lesion. Survival was estimated using Kaplan-Meier analysis.

\section{Results}

Thirty-seven operations were performed in 35 patients. The group consisted of 20 male and 15 female patients with a median age of 59 years (range 41-76).

The indication for treatment was colorectal metastases in 27 patients $(77 \%)$, other liver metastases in 6 and hepatocellular carcinoma (HCC) in 2 patients (table 1). The main indications for RFA was tumour proximity to major vascular structures and bilobular distribution (table 2). Nine patients had been treated for disseminated disease prior to the combined partial liver resection and RFA. Six 
Table I: Tumour histology in 37 combined partial liver resections and RFA in 35 patients

\begin{tabular}{ll}
\hline Metastases & \\
\hline Colorecta** & 27 \\
Carcinoid & 2 \\
Melanoma & 1 \\
Ovary carcinoma & 1 \\
Breast carcinoma & 1 \\
Grawitz & 1 \\
\hline Hepatocellular carcinoma & 2 \\
\hline
\end{tabular}

*Two patients were treated twice with RFA and partial liver resection

patients had received systemic chemotherapy, one patient had previously undergone partial liver resection, one RFA and one chemotherapy via hepatic artery infusion. Thirteen patients (37\%) were known to have relevant co-morbidity, including severe pulmonary and cardiac disorders, cirrhosis and diabetes mellitus. Co-morbidity was not associated with increased postoperative morbidity or mortality. Most patients were evaluated by preoperative multiphasic CT $(\mathrm{n}=34)$, but also by MRI $(\mathrm{n}=5)$ and PET scanning $(n=1)$. All but one patient were operated with curative intent, but none could be treated with partial liver resection alone to remove all lesions while leaving sufficient vital hepatic parenchyma.

One hundred fifty-eight primary and metastatic liver tumours were treated by either partial liver resection or RFA. Seventy-six lesions were resected with a mean $( \pm S D)$ of $2.1 \pm 1.8$ lesions per patient per laparotomy (range $1-$ 9). Seven patients $(19 \%)$ underwent a major resection (table 3). RFA was performed to ablate 82 unresectable liver tumours, with a mean of $2.2 \pm 1.5$ lesions per patient per laparotomy (range 1-7), and the median diameter of the treated lesions was $19 \mathrm{~mm}$ (range 5-50 mm). The Pringle manoeuvre was used in 4 patients. These were all cases in which a tumour was located near major vessels and vascular occlusion was used to reduce the heat sink effect. Median blood loss was $550 \mathrm{ml}$ (range 150-3500).

Table 2: Indication for RFA in 37 combined partial liver resections and RFA in 35 patients

\begin{tabular}{ll}
\hline Tumour proximity to major vascular structures & 13 \\
Bilobular tumour distribution & 12 \\
Recurrence after surgical treatment & 4 \\
Extrahepatic disease & 3 \\
Inadequate functional hepatic reserve & 3 \\
Cirrhosis & 2 \\
\hline Total & 37 \\
\hline \multirow{2}{*}{ *Two patients were treated twice with RFA and partial liver resection }
\end{tabular}

Median operating time was 240 minutes (range 120600).

Median hospital stay was 8 days (range 4-25). Twelve patients developed a total of 24 complications, resulting in an overall perioperative morbidity rate of 32\%. Minor complications included respiratory tract infection, pleural effusion, thrombosis, cholangitis, urinary tract infection and wound infection (table 4). Fourteen complications in 6 patients were considered major (major complication rate $16 \%$ ), including liver failure, biliary stricture, hepatic abscess, necrotizing pancreatitis, peritonitis, postoperative haemorrhage and pulmonary embolus. Seven complications in 6 patients were considered solely RFA-related (RFA-related morbidity 16\%), including biliary stricture, hepatic abscess and vascular damage. Three patients developed biliary stricture following local ablation. In 1 patient a metastasis treated by RFA was located in segment VIII, in the other 2 patients colorectal metastases in segment IV were treated by local ablation. In all 3 patients local ablation was performed centrally in the liver, resulting in a stricture of the left or right hepatic duct. These patients developed jaundice with peak bilirubin levels ranging from 74 to $940 \mu \mathrm{mol} / \mathrm{L}$. In all of these cases one or more ERCP procedures were performed for stenting of the biliary tract. Three patients developed hepatic abscesses, 2 of which were located at the site of ablation and, thus considered RFA-related. Treatment consisted of percutaneous drainage $(n=1)$ or drainage via laparotomy $(n=2)$. In one patient right portal vein thrombosis near the RFA lesion was diagnosed during analysis for severe ascites. In a second patient minor haemorrhage was observed near the RFA-lesion as result of hepatic artery damage (table 4).

In two patients major complications resulted in postoperative death (postoperative mortality rate 5.4\%). Both patients developed liver failure and died in spite of maximum supportive therapy. The first patient had Child-Pugh A cirrhosis as a result of hepatitis $\mathrm{C}$ and did not tolerate resection of segment IV and RFA of 2 hepatocellular carcinomas in segments VII and VIII. Postoperatively she developed an intrahepatic haematoma in the left lateral liver lobe due to persisting bleeding from wound tissue. This resulted in a hypovolumic shock requiring multiple blood transfusions, and liver failure. She developed an infected peritonitis (Staphylococcal aureus and Difteroids) and underwent explorative laparotomy during which necrotic liver parenchyma was resected. This did, however, not result in a clinical improvement and she eventually died due to fatal liver failure. The second patient, with normal preoperative liver function, underwent right hemihepatectomy with 9 colorectal metastases and RFA of a metastasis with a diameter of $20 \mathrm{~mm}$ in segment II/III. He was diagnosed with a liver abscess, liver failure and 
Table 3: Largest resection in 37 patients treated with combined partial liver resection and RFA

\begin{tabular}{ll}
\hline Major resection & \\
\hline $\begin{array}{l}\text { Extended left hemihepatectomy } \\
\text { Right hemihepatectomy }\end{array}$ & 1 \\
$\begin{array}{l}\text { Segmentectomy } \\
4 \text { segments } \\
3 \text { segments }\end{array}$ & 1 \\
\hline Minor resection & 3 \\
\hline $\begin{array}{l}\text { Segmentectomy } \\
2 \text { segments } \\
\text { I segment }\end{array}$ & \\
Metastasectomy & 5 \\
\hline Total & 14 \\
\hline
\end{tabular}

abdominal peritonitis. During relaparotomy a paracolic haematoma infected with Staphylococcal aureus and Streptococcus was removed. Autopsy revealed that death was due to septic shock secondary to necrotizing pancreatitis. In the middle hepatic vein partial thrombosis was observed. This was not related to the RFA procedure, since this metastasis was located deep in segment II/III. The patient did not have portal vein thrombosis.

Median follow-up in the entire study group was 13 months (range 1-46). The estimated 1-, 2- and 3-year

Table 4: Twenty-four complications in 12 patients after combined partial liver resection and RFA

\begin{tabular}{lll}
\hline Major & Number & RFA related \\
\hline Liver failure & 3 & 0 \\
Biliary stricture & 3 & 3 \\
Hepatic abscess & 3 & 2 \\
Peritoneal infection (S. Aureus) & 2 & 0 \\
Necrotising pancreatitis & 1 & 0 \\
Intrahepatic haematoma & 1 & 0 \\
Pulmonary embolus & 1 & 0 \\
\hline Minor & & \\
\hline Respiratory tract infection & 2 & 0 \\
Pleural effusion & 2 & 0 \\
Hepatic vein thrombosis & 1 & 0 \\
Hepatic artery damage & 1 & 1 \\
Cholangitis & 1 & 0 \\
Urine tract infection & 1 & 0 \\
Portal vein thrombosis & 1 & 1 \\
Wound infection & 1 & 0 \\
\hline Total & 24 & 7 \\
\hline
\end{tabular}

*Two patients were treated twice with RFA and partial liver resection overall survival rates were $84 \%, 70 \%$ and $43 \%$, respectively. Estimated disease-free 1-, 2- and 3-year survival rates were $57 \%, 38 \%$ and $20 \%$, respectively. Irradical resection was observed in 5 patients. In 4 patients the resection appeared irradical at histopathological examination, while in 1 patient optimal extrahepatic cytoreduction of stage IV ovarian carcinoma could not be achieved. During follow-up local tumour progression was observed in 10 RFA lesions (in 8 patients) as indicator of local treatment failure, resulting in a local success rate of $88 \%$. All tumours were colorectal metastases. Four of these tumours were larger than $3 \mathrm{~cm}$. Four other tumours were smaller, but were localized in the dome or centrally in the liver (segment IVA, VI or VII). For the remaining 2 tumours no explanation for incomplete ablation could be found. Median time to local tumour progression was 5 months. Seventeen patients (46\%) developed hepatic recurrence, while 15 patients (41\%) developed extrahepatic disease. The median number of liver tumours treated by local ablation per operation was 4 (range $2-10$ ). In patients with $\geq 4$ tumours recurrence was $58 \%$, while in patients with $<4$ tumours recurrence was 33\%, respectively $(\mathrm{p}=0.12)$.

One single patient was treated for ovarian carcinoma stage IV by multimodality therapy including chemotherapy (Taxol), cytoreductive surgery and combined partial liver resection and RFA. Optimal extrahepatic cytoreduction (< $1 \mathrm{~cm}$ residual disease) could not be achieved and after 4 months recurrence in the liver was observed. Two other patients were also known to have extrahepatic disease (table 2). In the first patient two colorectal lung metastases were additionally removed. Three months after resection and RFA hepatic recurrence was observed and after 6 months local tumour progression and new extrahepatic lesions were diagnosed. The second patient underwent an additional metastasectomy of an omental metastasis of a Grawitz tumour. After 15 months of follow-up the patient is still free of disease.

\section{Discussion}

Several series have been published on combined resection and RFA [7,18-22]. However, all of these involved monoinstitutional experience of large cancer centres. We report the results from a Dutch multi-institutional database, involving 8 hospitals, including 1 cancer centre. Although all resections and RFA procedures were performed by experienced liver surgeons, this series may reflect daily practice more accurately.

In the current series, we observed a morbidity rate of $32 \%$ (major complication rate $16 \%$ ) and a mortality rate of $5.4 \%$. In the same period 87 patients were solely treated by RFA in the hospitals involved in this study. In this group the mortality rate after RFA was $0 \%$ and the RFA 
related morbidity was $9.8 \%$ [11]. In a series from the University Medical Centre Utrecht the mortality and morbidity rate, following partial liver resection were $5.8 \%$ and $23 \%$ respectively. The 5 -year survival rate after liver resection for colorectal metastases was 38\%. [23]. Better figures were reported by Pawlik et al, with a postoperative complication rate of $19.8 \%$ and an overall mortality rate of 2.3\% in 172 patients treated with partial liver resection and RFA, among which 54\% were major hepatectomies [7], while numbers similar to ours were found by Mulier et al, reporting a complication rate of $31.8 \%$ and a mortality rate of $4.5 \%$ in patients treated with open RFA in combination with cryotherapy, partial hepatic resection or extrahepatic resection [8]. Elias et al, did not observe any postoperative deaths in 63 patients and found a morbidity rate of $27 \%$ [21]. These series show that morbidity and mortality rates of combined partial liver resection and RFA are comparable with those of partial liver resection alone [1-3].

In large series the 5 -year survival is $36-39 \%$ after partial liver resection alone as treatment for colorectal liver metastasis, which is still considered the gold standard $[3,4,24]$. Although few series have been published describing long-term results after RFA, the results appear promising. Solbiati et al, report a 3-year survival rate of $46 \%$ and Gillams et al, report a 5-year survival rate of $30 \%$ $[12,13,25]$. Abdalla et al, compared RFA only, RFA + resection, resection only and chemotherapy retrospectively in a large series $(n=418)[20]$. They described that the combination of partial liver resection and RFA in 101 patients provided only modest survival benefit over chemotherapy alone and was not different than following RFA only in patients with colorectal liver metastases. Survival after resection only was significantly better than all other treatment modalities. In our series 3-year overall survival was $43 \%$, while the disease-free survival was $20 \%$. Due to the number of patients with various diseases in our series, conclusions with regard to oncological outcome cannot be drawn from the present study.

Patient selection strongly improves the results in liver surgery. Since substantial morbidity and mortality are introduced, patients should be selected rigorously when treated with combined resection and RFA. In our series, 1 patient died after right hepatectomy and controlateral RFA of a colorectal metastasis measuring $20 \mathrm{~mm}$. For patients treated by combined major resection and RFA, percutaneous RFA combined with portal vein embolization followed by hepatectomy one month later should ideally be considered [26].

With regard to long term outcome the following aspects should be taken into consideration. The total number of tumours has been identified as a factor affecting time to recurrence after resection alone [27-29] or combined resection and RFA $[7,20]$. In this series, there was a trend for an increased recurrence rate in patients treated for $\geq 4$ tumours $(p=0.12)$. Since tumour diameter is also a risk factor for local recurrence after RFA, only small tumours should be treated by RFA when combined with resection $[12,30]$. A cut off point of $30 \mathrm{~mm}$ diameter has been proposed [21]. In general percutaneous RFA should not be performed, since this approach results in increased local recurrence [30]. A fourth risk factor affecting long term survival is extrahepatic disease [28,31]. Although a 5-year survival rate of $28 \%$ after "R0" resection of extrahepatic disease in conjunction with partial hepatectomy for colorectal liver metastases has been published, this intended "R0" resection could not be performed in $50 \%$ of operated patients [32]. Therefore, in our opinion extrahepatic disease is a relative contraindication for combined resection and RFA. Only in patients with intraoperative potential for "R0" resection and simple extrahepatic disease after meticulous exploration, combined resection and RFA should be considered. We have treated only 3 patients with extrahepatic disease in our series with variable outcome. A fifth factor influencing survival might be chemotherapy. Neoadjuvant chemotherapy allows 10$15 \%$ of patients with unresectable colorectal liver metastases to be rescued by liver surgery [33]. In a series of Elias, et al the strategy of combined partial liver resection and RFA with perioperative chemotherapy appeared favourable by doubling the median survival (from 18 to 36 months), when compared to similar unresectable colorectal patients treated by chemotherapy alone [21]. RFA followed by chemotherapy seems feasible, but no randomised studies on its additive value are available at present $[21,34]$.

\section{Conclusion}

Combining partial liver resection and RFA augments the number of patients who can be treated surgically. But this strategy should only be performed following strict patient selection and within the context of prospective clinical trials.

\section{Competing interests}

The author(s) declare that they have no competing interests.

\section{Authors' contributions}

BF designed the study, carried out the data acquisition and drafted the manuscript. MJ and FvD carried out the data acquisition and participated in drafting and revising the manuscript. RvH and TvG participated in the design of the study and in drafting and revising the manuscript. IBR conceived of the study and coordinated the draft and revision of the manuscript. All authors read and approved the final manuscript. 


\section{References}

I. Belghiti J, Hiramatsu K, Benoist S, Massault P, Sauvanet A, Farges O: Seven hundred forty-seven hepatectomies in the 1990s: an update to evaluate the actual risk of liver resection. J Am Coll Surg 2000, 191:38-46.

2. Jarnagin WR, Gonen M, Fong Y, DeMatteo RP, Ben-Porat L, Little S, Corvera C, Weber S, Blumgart LH: Improvement in perioperative outcome after hepatic resection: analysis of I,803 consecutive cases over the past decade. Ann Surg 2002, 236:397-407.

3. Ballantyne GH, Quin J: Surgical treatment of liver metastases in patients with colorectal cancer. Cancer 1993, 71:4252-4266.

4. Fong Y, Cohen AM, Fortner JG, Enker WE, Turnbull AD, Coit DG Marrero AM, Prasad M, Blumgart LH, Brennan MF: Liver resection for colorectal metastases. J Clin Oncol 1997, I 5:938-946.

5. Elias D, Cavalcanti de Albuquerque $A$, Eggenspieler $P$, Plaud $B$, Ducreux M, Spielmann M, Theodore C, Bonvalot S, Lasser P: Resection of liver metastases from a noncolorectal primary: indications and results based on 147 monocentric patients. J Am Coll Surg 1998, 187:487-493.

6. Elias D, Baton O, Sideris L, Matsuhisa T, Pocard M, Lasser P: Local recurrences after intraoperative radiofrequency ablation of liver metastases: a comparative study with anatomic and wedge resections. Ann Surg Oncol 2004, I I:500-505.

7. Pawlik TM, Izzo F, Cohen DS, Morris JS, Curley SA: Combined resection and radiofrequency ablation for advanced hepatic malignancies: results in 172 patients. Ann Surg Oncol 2003 , 10:1059-1069.

8. Mulier S, Mulier P, Ni Y, Miao Y, Dupas B, Marchal G, De Wever I, Michel L: Complications of radiofrequency coagulation of liver tumours. Br J Surg 2002, 89: I 206-I222.

9. Livraghi T, Solbiati L, Meloni MF, Gazelle GS, Halpern EF, Goldberg SN: Treatment of focal liver tumors with percutaneous radio-frequency ablation: complications encountered in a multicenter study. Radiology 2003, 226:44 I-45I.

10. Curley SA, Marra P, Beaty K, Ellis LM, Vauthey IN, Abdalla EK, Scaife C, Raut C, Wolff R, Choi H, Loyer E, Vallone P, Fiore F, Scordino F De Rosa V, Orlando R, Pignata S, Daniele B, Izzo F: Early and late complications after radiofrequency ablation of malignant liver tumors in 608 patients. Ann Surg 2004, 239:450-458.

II. Jansen MC, van Duijnhoven FH, van Hillegersberg $R$, Rijken $A$, van Coevorden F, van der Sijp J, Prevoo W, van Gulik TM: Adverse effects of radiofrequency ablation of liver tumours in the Netherlands. Br J Surg 2005, 92: | 248-| 254.

12. Solbiati L, Livraghi T, Goldberg SN, lerace T, Meloni F, Dellanoce M, Cova L, Halpern EF, Gazelle GS: Percutaneous radio-frequency ablation of hepatic metastases from colorectal cancer: longterm results in I I 7 patients. Radiology 200I, 22 I: I59- I66.

13. Livraghi T, Solbiati L, Meloni F, lerace T, Goldberg SN, Gazelle GS: Percutaneous radiofrequency ablation of liver metastases in potential candidates for resection: the "test-of-time approach". Cancer 2003, 97:3027-3035.

14. Van Duijnhoven FH, Jansen MC, Junggeburt J, van Hillegersberg R, Rijken A, van Coevorden F, van der Sijp JR, van Gulik TM, Slooter GD, Klaase JM, Putter $\mathrm{H}$, Tollenaar RA: Factors influencing local success rate of radiofrequency ablation of colorectal liver metastases. Ann Surg Oncol in press.

I5. Curley SA, Izzo F, Delrio P, Ellis LM, Granchi J, Vallone P, Fiore F, Pignata $S$, Daniele $B$, Cremona F: Radiofrequency ablation of unresectable primary and metastatic hepatic malignancies: results in 123 patients. Ann Surg 1999, 230: I-8.

16. Goldberg SN, Charboneau JW, Dodd GD 3rd, Dupuy DE, Gervais DA, Gillams AR, Kane RA, Lee FT Jr, Livraghi T, McGahan JP, Rhim H, Silverman SG, Solbiati L, Vogl TJ, Wood BJ, International Working Group on Image-Guided Tumor Ablation: International Working Group on Image-Guided Tumor Ablation. Image-guided tumor ablation: proposal for standardization of terms and reporting criteria. Radiology 2003, 228:335-345

17. Balzan S, Belghiti J, Farges O, Ogata S, Sauvanet A, Delefosse D, Durand F: The "50-50 criteria" on postoperative day 5: an accurate predictor of liver failure and death after hepatectomy. Ann Surg 2005, 242:824-828.

18. Evrard S, Becouarn Y, Fonck M, Brunet R, Mathoulin-Pelissier S, Picot $V$ : Surgical treatment of liver metastases by radiofrequency ablation, resection, or in combination. Eur J Surg Oncol 2004, 30:399-406.
19. Elias D, Goharin A, El Otmany A, Taieb J, Duvillard P, Lasser P, de Baere $T$ : Usefulness of intraoperative radiofrequency thermoablation of liver tumours associated or not with hepatectomy. Eur J Surg Oncol 2000, 26:763-769.

20. Abdalla EK, Vauthey JN, Ellis LM, Ellis V, Pollock R, Broglio KR, Hess $\mathrm{K}$, Curley SA: Recurrence and outcomes following hepatic resection, radiofrequency ablation, and combined resection/ ablation for colorectal liver metastases. Ann Surg 2004, 239:818-825

21. Elias D, Baton O, Sideris L, Boige V, Malka D, Liberale G, Pocard M, Lasser $P$ : Hepatectomy plus intraoperative radiofrequency ablation and chemotherapy to treat technically unresectable multiple colorectal liver metastases. J Surg Oncol 2005 , 90:36-42.

22. Navarra G, Ayav A, Weber JC, Jensen SL, Smadga C, Nicholls JP, Habib NA, Jiao LR: Short- and-long term results of intraoperative radiofrequency ablation of liver metastases. Int J Colorectal Dis 2005, 20:521-528.

23. Fioole B, Liem MS, Hennipman A, Borel Rinkes IH: Partial liver resections: mortality, morbidity and risk factors for postoperative complications in 133 patients/I37 operations; Utrecht University Medical Center 199//2000. Ned Tijdschr Geneeskd 2002, I46:210-2I3.

24. Scheele J, Stangl R, Altendorf-Hofmann A, Gall FP: Indicators of prognosis after hepatic resection for colorectal secondaries. Surgery 1991, I 1 0: I3-29.

25. Gillams AR, Lees WR: Radio-frequency ablation of colorectal liver metastases in 167 patients. Eur Radiol 2004, I 4:226I-2267.

26. Elias D, Santoro R, Ouellet JF, Osmak L, de Baere T, Roche A: Simultaneous percutaneous right portal vein embolization and left liver tumor radiofrequency ablation prior to a major right hepatic resection for bilateral colorectal metastases. Hepatogastroenterology 2004, 5 I : | 788- I79|

27. Nordlinger B, Guiguet M, Vaillant JC, Balladur P, Boudjema K, Bachellier $P$, Jaeck D: Surgical resection of colorectal carcinoma metastases to the liver. A prognostic scoring system to improve case selection, based on 1568 patients. Association Francaise de Chirurgie. Cancer 1996, 77: I 254- 1262.

28. Fong Y, Fortner J, Sun RL, Brennan MF, Blumgart LH: Clinical score for predicting recurrence after hepatic resection for metastatic colorectal cancer: analysis of $100 \mathrm{I}$ consecutive cases. Ann Surg 1999, 230:309-318.

29. Sasaki A, Iwashita Y, Shibata K, Matsumoto T, Ohta M, Kitano S: Analysis of Preoperative Prognostic Factors for Long-term Survival After Hepatic Resection of Liver Metastasis of Colorectal Carcinoma. J Gastrointest Surg 2005, 9:374-380.

30. Mulier S, Ni Y, Jamart J, Ruers T, Marchal G, Michel L: Local recurrence after hepatic radiofrequency coagulation: multivariate meta-analysis and review of contributing factors. Ann Surg 2005, 242: I58-17|.

3I. Iwatsuki S, Dvorchik I, Madariaga JR, Marsh JW, Dodson F, Bonham AC, Geller DA, Gayowski TJ, Fung JJ, Starzl TE: Hepatic resection for metastatic colorectal adenocarcinoma: a proposal of a prognostic scoring system. J Am Coll Surg 1999, 189:291-299.

32. Elias D, Sideris L, Pocard M, Ouellet JF, Boige V, Lasser P, Pignon JP, Ducreux M: Results of $\mathrm{RO}$ resection for colorectal liver metastases associated with extrahepatic disease. Ann Surg Oncol 2004, I I :274-280.

33. Adam R, Delvart V, Pascal G, Valeanu A, Castaing D, Azoulay D, Giacchetti S, Paule B, Kunstlinger F, Ghemard O, Levi F, Bismuth H: Rescue surgery for unresectable colorectal liver metastases downstaged by chemotherapy: a model to predict long-term survival. Ann Surg 2004, 240:644-657.

34. Scaife CL, Curley SA, Izzo F, Marra P, Delrio P, Daniele B, Cremona F, Gershenwald JE, Chase JL, Lozano RD, Patt YZ, Fornage BD, Vauthey JN, Woodall ML, Gonzalez KB, Ellis LM: Feasibility of adjuvant hepatic arterial infusion of chemotherapy after radiofrequency ablation with or without resection in patients with hepatic metastases from colorectal cancer. Ann Surg Oncol 2003, 10:348-354. 